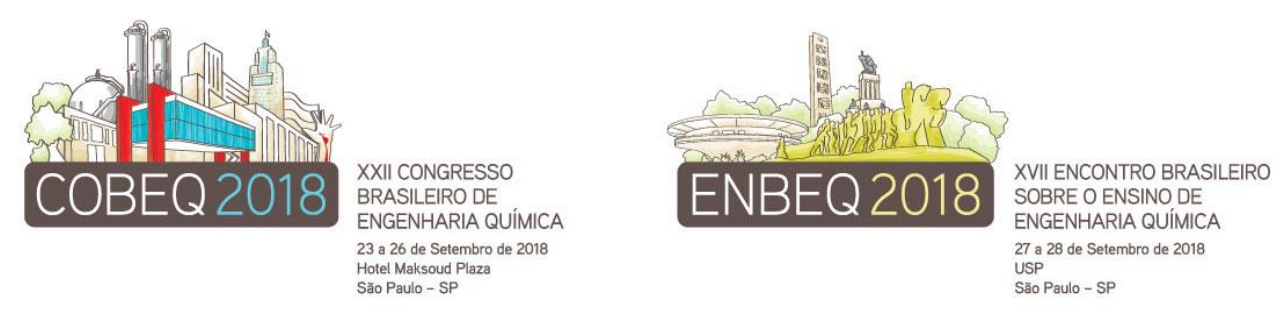

\title{
COMPARAÇÃO DO DESEMPENHO CATALÍTICO A PARTIR DA COMBINAÇÃO DE LIPASES LIVRES E IMOBILIZADAS NA SÍNTERE DE ÉSTERES ETÍLICOS
}

\author{
ARAKI CA ${ }^{1}$, MARCUCCI SMP ${ }^{1}$, MAEDA CH $^{1}$, ARROYO PA $^{1}$, ZANIN GM $^{1}$ \\ ${ }^{1}$ Universidade Estadual de Maringá, Centro de Tecnologia, Departamento de Engenharia \\ Química \\ E-mail para contato: carina.araki@gmail.com
}

\begin{abstract}
RESUMO - O objetivo deste trabalho foi avaliar o efeito do uso combinado da lipase de Burkholderia cepacia (LBC) com a de Thermomyces lanuginosus (LTL) na produção de ésteres etílicos do óleo da polpa da macaúba. Os resultados obtidos por meio das enzimas livres foram comparados àqueles observados paras as enzimas imobilizadas. Em ambos os casos, observou-se a sinergia entre os biocatalisadores. $O$ procedimento de imobilização influenciou o desempenho biocatalítico: $77,7 \pm 3,2 \%$ de

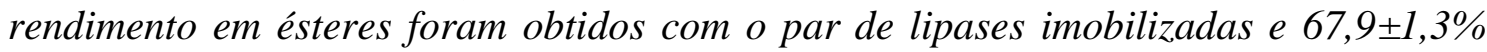
com o par de livres.
\end{abstract}

\section{INTRODUÇÃO}

Nos últimos anos, a produção enzimática de biodiesel tem atraído atenção dos pesquisadores por apresentar diversas vantagens em relação aos métodos químicos. Exemplos disso são: a possibilidade de conduzir as reações com a quantidade estequiométrica de álcool; de trabalhar em condições amenas de temperatura e pressão; e de empregar matérias-primas com elevado teor de ácidos graxos livres (Poppe et al., 2015).

Nessa técnica, o emprego de mais de um biocatalisador pode viabilizar maiores rendimentos em ésteres comparados àqueles alcançados por uma única lipase. Tal fato pode ocorrer devido às diferenças que essas enzimas apresentam em relação à especificidade pela quebra das ligações ésteres em determinadas posições dos glicerídeos, bem como à especificidade a um tipo específico de ácido graxo (Poppe et al., 2015; Su et al., 2015).

Outro aspecto da biocatálise é que as enzimas podem ser utilizadas na forma imobilizada, o que permite a recuperação e reutilização do biocatalisador. Para tanto, normalmente, é preciso selecionar um suporte com elevada área específica e tamanho de poros adequado, como pode ser o caso da zeólita ZSM-5 com estrutura hierárquica de poros (Mitchell et al., 2011). 


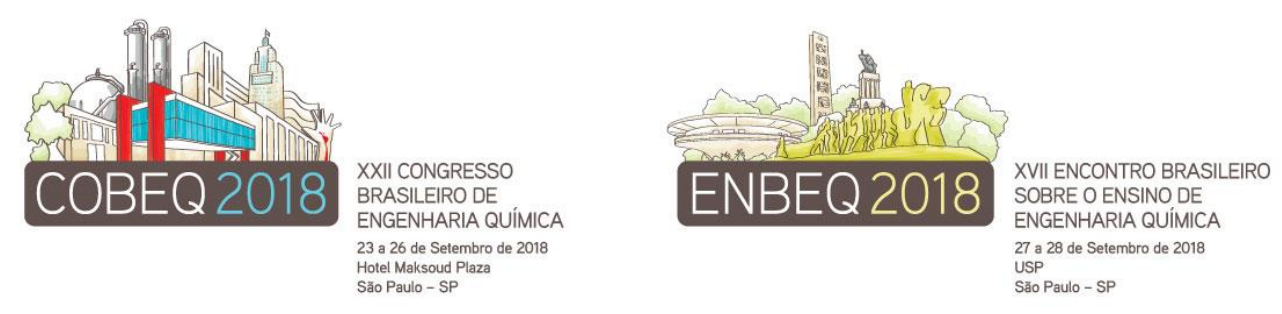

Dessa forma, o objetivo desse trabalho foi avaliar o efeito do uso combinado da lipase de Burkholderia cepacia (LBC) com a de Thermomyces lanuginosus (LTL), livres e imobilizadas, na obtenção de ésteres etílicos do óleo de macaúba.

\section{MATERIAIS E MÉTODOS}

\subsection{Materiais}

Lipases de Thermomyces lanuginosus $\left(\geq 100.000 \mathrm{U} \mathrm{g}^{-1}\right.$, Sigma-Aldrich) e de Burkholderia cepacia (Amano Lipase PS, $\geq 30.000 \mathrm{U} \mathrm{g}^{-1}$, Sigma-Aldrich). Zeólita ZSM-5 com adição de mesoporos (razão $\mathrm{Si} / \mathrm{Al} \cong 17$, OAS) modificada com 3mercaptopropiltrimetoxisilano (área específica de $252 \mathrm{~m}^{2} \mathrm{~g}^{-1}$ e distribuição de tamanho de poros centralizada em $12 \mathrm{~nm}$ ). Óleo da polpa de macaúba (índice de acidez de 60,3 \pm 0,1 mg $\mathrm{KOH} \mathrm{g}{ }^{-1}$, massa molar de 617,7 $\pm 0,3 \mathrm{~g} \mathrm{~mol}^{-1}$, Montes Claros, MG), etanol (99,9\%, Anidrol) e tricosanoato de metila (99\%, Sigma-Aldrich)

\subsection{Procedimento de Imobilização}

Foram preparadas soluções enzimáticas, contendo cerca de $10 \mathrm{mg}$ de proteína em 25 $\mathrm{mL}$ de tampão fosfato ( $\mathrm{pH} 7,0)$. Essas soluções foram adicionadas a $1 \mathrm{~g}$ de suporte em erlemmeyers de $50 \mathrm{~mL}$. Os frascos foram mantidos em banho Dubnoff com agitação a $25^{\circ} \mathrm{C}$, por 2 horas. Depois, permaneceram por 24 horas a $4{ }^{\circ} \mathrm{C}$. As suspensões foram lavadas com

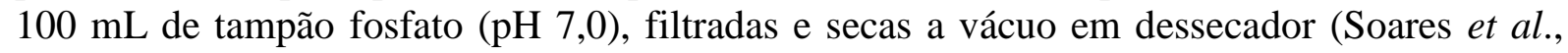
2004).

\subsection{Atividade de Hidrólise}

Em erlenmeyers de $125 \mathrm{~mL}, 0,1 \mathrm{~g}$ de enzima imobilizada ou $1 \mathrm{~mL}$ de solução enzimática foi adicionado a $2 \mathrm{~mL}$ de tampão fosfato $(\mathrm{pH} \mathrm{7,0)} \mathrm{e} 5 \mathrm{~mL}$ de uma emulsão de goma arábica e azeite de oliva. Os frascos foram mantidos com agitação por 10 minutos a $37^{\circ} \mathrm{C}$. As amostras foram tituladas com $\mathrm{KOH} 0,02 \mathrm{~mol} \mathrm{~L}^{-1}$ e indicador fenolftaleína. A atividade específica $\left(\mathrm{U} \mathrm{mg}^{-1}\right)$ foi definida como a quantidade de mmol de ácido graxo formado por minuto, por mg de proteína presente no biocatalisador (Soares et al., 2004).

\subsection{Reações Para Obtenção de Ésteres}

Em reatores de vidro encamisado de $30 \mathrm{~mL}$, foram adicionados $10 \mathrm{~g}$ de óleo, 2,23 mL de etanol (razão molar de $1: 3)$ e $6 \%\left(\mathrm{~g} \mathrm{~g}^{-1}\right)$ de biocatalisador em relação à massa de óleo. Os sistemas foram mantidos com agitação magnética, a $45^{\circ} \mathrm{C}$. No caso das misturas de lipases, utilizou-se a razão mássica de LBC : LTL de 1:3. Os produtos reacionais foram analisados por cromatografia a gás. O tricosanoato de metila (C23) foi utilizado como padrão interno para quantificação dos ésteres formados na reação.

\section{RESULTADOS E DISCUSSÃO}

\subsection{Atividade de Hidrólise}

Na Tabela 1 pode-se observar que os valores de atividade específica para as lipases 

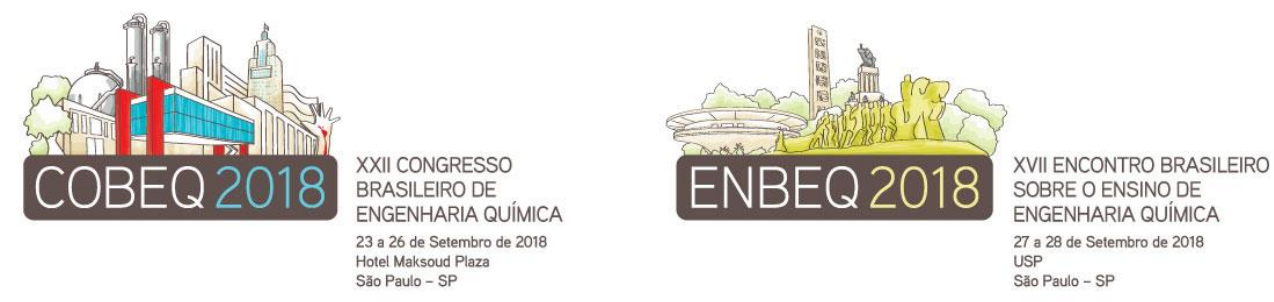

imobilizadas foram menores, pois os procedimentos de imobilização podem provocar mudanças conformacionais nas enzimas para uma forma inativa, bem como ocasionar impedimentos estéricos (Villeneuve et al., 2000).

Tabela 1 - Atividade específica das lipases na reação de hidrólise do azeite de oliva a $37^{\circ} \mathrm{C}$.

\section{Atividade}

Biocatalisador* $^{*}$

$\left(\mathrm{U} \mathrm{mg}^{-1}\right)$

\begin{tabular}{ccc}
\cline { 2 - 3 } & Livre & Imobilizada \\
\hline LBC & $115 \pm 2$ & $66 \pm 9$ \\
LTL & $95 \pm 2$ & $68 \pm 8$ \\
\hline
\end{tabular}

${ }^{*}$ LTL = lipase de Thermomyces lanuginosus $;$ LBC = lipase de Burkholderia cepacia .

\subsection{Reações Para Obtenção de Ésteres}

De acordo com a Figura 1a e 1b, em 48 horas, os maiores rendimentos em ésteres foram obtidos com o uso combinado tanto das lipases livres, quanto das imobilizadas.
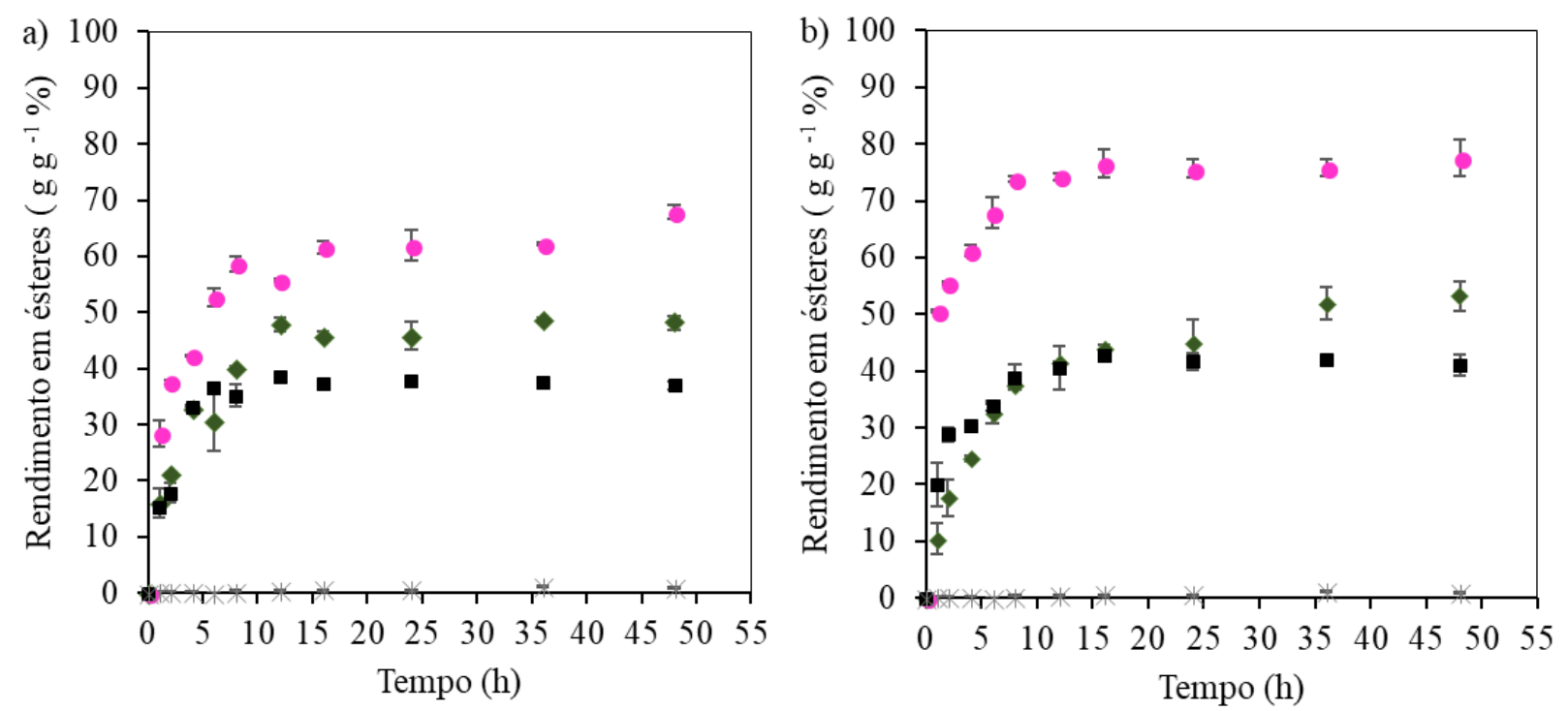

Figura 1 - Rendimentos em ésteres etílicos do óleo de macaúba obtidos por meio do uso individual da LBC (־-), da LTL (־), da combinação destas (——) e sem biocatalisador $\left({ }^{-*}\right)$ a) Lipases livres. b) Lipases imobilizadas.

Esses resultados demonstram que houve sinergia entre os biocatalisadores estudados. Tal comportamento pode ocorrer porque a LBC é uma lipase não regiosseletiva e a LTL é 1,3regiosseletiva (Su et al., 2015). Ao mesmo tempo, enquanto a TLL é muito ativa em relação à maioria dos grupos acil, independentemente do comprimento da cadeia ou do grau de insaturação, a BCL apresenta alta especificidade em relação ao ácido caprílico e palmítico (Chang et al., 1999; Fernandez-Lafuente et al., 2010; Poppe et al., 2015). 


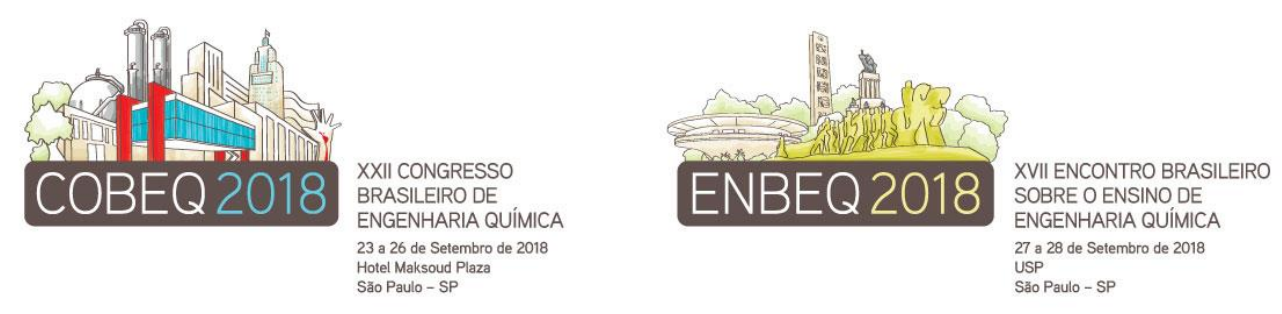

Ainda pode-se notar a melhora no desempenho catalítico das enzimas após imobilizadas. Isso pode ter ocorrido devido ao processo de imobilização por ligação covalente, pois este pode restringir as mudanças conformacionais das enzimas, proporcionando maior estabilidade à temperatura e à presença de álcoois de cadeia curta em relação às enzimas livres (Salehi et al., 2016).

\section{CONCLUSÕES}

Com base nos resultados obtidos neste trabalho, foi demonstrado que, nas condições estudadas, o uso da mistura de LBC com LTL proporciona maior rendimento em ésteres do que os obtidos com as lipases utilizadas separadamente. Também ficou evidente que o processo de imobilização utilizado influenciou positivamente o desempenho catalítico das lipases, de modo que foram obtidos rendimentos maiores do que os observados para as enzimas livres.

\section{REFEÊNCIAS}

CHANG Q L, LEE C H, PARKIN K L, Comparative selectivities of immobilized lipases from Pseudomonas cepacia and Candida antarctica (fraction B) for esterification reactions with glycerol and glycerol analogues in organic media. Enzyme Microb. Technol. v. 25, p. 290-297, 1999.

FERNANDEZ-LAFUENTE R, Lipase from Thermomyces lanuginosus: Uses and prospects as na industrial biocatalyst. J. Mol. Catal. B Enzym, v. 62, p. 197-212, 2010.

MITCHELL S, PÉREZ-RAMÍREZ J, Mesoporous zeolites as enzyme carriers: Synthesis, characterization, and application in biocatalysis. Catal. Today, v.168, p. 28-37, 2011.

POPPE $\mathrm{K}$, MATTE $\mathrm{C} \mathrm{R}$, PERALBA $\mathrm{M}$ do $\mathrm{C} \mathrm{R}$, FERNANDEZ-LAFUENTE $\mathrm{R}$, RODRIGUES R C, AYUB M A Z, Optimization of ethyl ester production from olive and palm oils using mixtures of immobilized lipases. Appl. Catal. A Gen, v. 490 p. 50-56, 2015.

SALEHI Z, GHAHFAROKHI H H, KODADADI A A, RAHIMNIA R, Thiol and urea functionalized magnetic nanoparticles with highly enhanced loading capacity and thermal stability for lipase in transesterification. J. Ind. Eng. Chem, v. 35, p. 224-230, 2016.

SOARES C M F, DOS SANTOS O A, OLIVO J E, DE CASTRO H F, DE MORAES F F, ZANIN G M, Influence of the alkyl-substituted silane precursor on sol-gel encapsulated lipase activity. Appl. Biochem. Biotechnol, v. 29, p. 69-79, 2004.

SU F, PENG C, LI G L, XU L, YAN Y J, Biodiesel production from woody oil catalyzed by Candida rugosa lipase in ionic liquid. Renew. Energy, v. 90, p. 329-335, 2016.

VILLENEUVE P, MUDERHWA J M, GRAILLE J, HAAS M J, Customizing lipases for biocatalysis: a survey of chemical, physical and molecular biological approaches. J. Mol. Catal. B Enzym, v. 9, p. 113-148, 2000. 